\title{
Comparing different intensities of active referral to smoking cessation services in promoting smoking cessation among community smokers: a study protocol of a cluster randomized controlled trial
}

Xue Weng ${ }^{1}$, Man Ping Wang ${ }^{1 *}$ D, Yi Nam Suen ${ }^{2}$, William Ho Cheung $\mathrm{Li}^{1}$, Yongda Wu', Derek Yee Tak Cheung ${ }^{1}$, Antonio Cho Shing Kwong ${ }^{3}$, Vienna Wai Yin Lai ${ }^{3}$, Sophia Siu Chee Chan ${ }^{1}$ and Tai Hing Lam ${ }^{4}$

\begin{abstract}
Background: Actively referring smokers to smoking cessation (SC) services could increase quitting and is scalable for the population. The objective of this study is to compare 2 different intensities of SC active referral for smokers in the community of Hong Kong.

Methods/design: This is a single-blind, parallel 3-armed cluster randomized controlled trial (CRCT) consisting of high-intensity SC active referral (HAR Group), low-intensity SC referral by text messaging on promoting SC services use (Text Group) and a control group receives general very brief advice. Biochemically validated daily smokers will be proactively recruited in the community from 68 clusters (recruitment sessions). The primary outcome is self-reported 7-days point prevalence abstinence (PPA) at the 3- and 6- month follow-ups. Secondary outcomes are SC service use, smoking reduction rate (SRR, daily cigarette consumption reduced by $\geq 50 \%$; excluding quitters) and biochemically validated quit rate (exhaled $\mathrm{CO}<4 \mathrm{ppm}$ and salivary cotinine $<10 \mathrm{ng} / \mathrm{ml}$ ). Outcome assessors and data analysts will be blinded to group allocation. Intention-to-treat principle and Generalized Estimating Equation (GEE) regressions will be used for data analysis.

Discussion: This will be the first trial on evaluating the efficacy of the 2 different intensities of SC active referral on smoking cessation in community smokers. It is anticipated that the results from this trial can provide evidence to the effectiveness of high-intensity active referral to SC services and low intensity SC referral by using text messaging in achieving smoking abstinence.
\end{abstract}

Trial registration: ClinicalTrials.gov Identifier: NCT02804880, June 17, 2016.

Keywords: Smoking cessation, Active referral, Community smoker, Randomized controlled trial

\footnotetext{
* Correspondence: mpwang@hku.hk

${ }^{1}$ School of Nursing, University of Hong Kong, 4/F, William MW Block, 21

Sassoon Road, Pokfulam, Hong Kong SAR

Full list of author information is available at the end of the article
}

(c) The Author(s). 2018 Open Access This article is distributed under the terms of the Creative Commons Attribution 4.0 International License (http://creativecommons.org/licenses/by/4.0/), which permits unrestricted use, distribution, and reproduction in any medium, provided you give appropriate credit to the original author(s) and the source, provide a link to the Creative Commons license, and indicate if changes were made. The Creative Commons Public Domain Dedication waiver (http://creativecommons.org/publicdomain/zero/1.0/) applies to the data made available in this article, unless otherwise stated. 


\section{Background}

Despite decades of public health education and interventions on smoking cessation (SC), tobacco use remains the leading cause of preventable death causing over 7 million deaths worldwide every year [1]. Recent data indicates a decrease in the overall smoking prevalence but still with around 615,000 daily cigarette smokers in Hong Kong in 2017 [2]. Evidence has shown that smokers received SC services increases successful rate in quitting [3-6]. Although a variety of free SC services (e.g. quit-lines, clinics) are available in Hong Kong, the utility rate is low and only $14.2 \%$ of smokers had ever used [2]. Low-cost, easy accessibility and effective SC services are warranted to provide advice, medication, and support for people to quit smoking [7].

Referring smokers to SC services is one of the cheap and scalable strategies that can maximize usage of public cessation counselling and treatment. Most of current SC services depend on passive referral strategies that require smokers to seek assistance on their own, such as calling the quit-line or attending the SC clinics [8]. Unlike passive referrals that rely on smokers' self-initiation, active referral emphasizes physicians or other healthcare professionals efforts to refer smokers to SC services directly $[9,10]$. Allowance for smokers to choose their preferred service providers and cessation methods might also improve smokers' engagement in the service and hence enhance the outcomes [11]. Proactive referral approach can help overcome the barrier of self-initiation as most community smokers quit on their own without SC services [12]. Our previous randomized controlled trial (RCT) showed that moderate active referral of SC services significantly increased smoking abstinence rate at 6 months when compared with brief general SC advice (17.2\% vs. $11.5 \%, p=0.02$ ) [11].

Comparing with traditional telephone cessation assistance, interventions delivered via text messaging are more convenient and accessible, which could potentially extend the reach to SC services [4] and promote SC [13-15]. A recent meta-analysis of 15,593 smokers (20 RCTs) showed that the overall odds of smoking abstinence in text messaging group were 1.37 times higher than the control group [16]. The intensity of interventions in previous RCTs varies, in terms of the frequency, intensity and duration of text messaging in the intervention period, the degree and methods for personalization and tailoring of the text messaging. Substantial evidence has shown that intensive interventions produce more abstinence than less intensive interventions in the clinical setting [4]. Therefore, it is assumed that active referral intervention delivered via high-intensity text messaging will also result in more abstinence when compared with low-intensity text messaging. This study aims to evaluate the effectiveness of 2 different intensities of active referral interventions: (1) high-intensity active referral to SC services and (2) low-intensity SC service referral by using text messaging. The control group will receive general brief SC advice.

\section{Methods/design \\ Overview of design}

This is a single-blinded, parallel 3-armed cluster RCT (cRCT) on 1200 smokers participated in the Hong Kong 7th "Quit to Win" (QTW) Contest conducted in 2016-17. The QTW Contest [11, 17-20] is organized by the Hong Kong Council on Smoking and Health (COSH) each year since 2009 to promote SC in the general community. Based on the recruitment sessions, participants will be randomly assigned to 1 of the following 3 conditions: (1) high intensity active referral to SC services (HAR Group); (2) low intensity SC service referral using text messaging on promoting and encouraging SC service use (Text Group); or (3) general brief SC advice (Control Group). All participants will receive a 12-page self-help SC booklet at baseline. HAR Group and Text Group will also receive AWARD model guided SC advice with a warning leaflet and a referral card. Control Group will only receive general brief advice at baseline. The trial will follow the Consolidated Standards of Reporting Trials (CONSORT) criteria for the design [21] and is shown in Fig. 1.

\section{Participants}

Inclusion criteria:

- Hong Kong residents aged 18 or above;

- Currently smoking at least 1 cigarette per day in the past 3 months;

- Able to communicate in Cantonese (and read Chinese);

- Exhaled carbon monoxide (CO) 4 ppm or above as validated by $\mathrm{CO}$ Smokerlyzer;

- Intend to quit or reduce smoking [22];

- Having a local phone number for follow-up.

\section{Exclusion criteria:}

- Having physical or cognitive difficulties in communication;

- Currently following other SC programs.

\section{Recruitment}

A total of 68 recruitment activities will be organized in all 18 Hong Kong districts aiming to recruit 1200 participants over 3 months. University students majoring in nursing, public health and related fields and volunteers of non-governmental organizations (NGOs) will be trained as SC ambassadors in a two-day workshop ( $8 \mathrm{~h}$ each) for onsite recruitment. To reach as many as eligible smokers, booths 


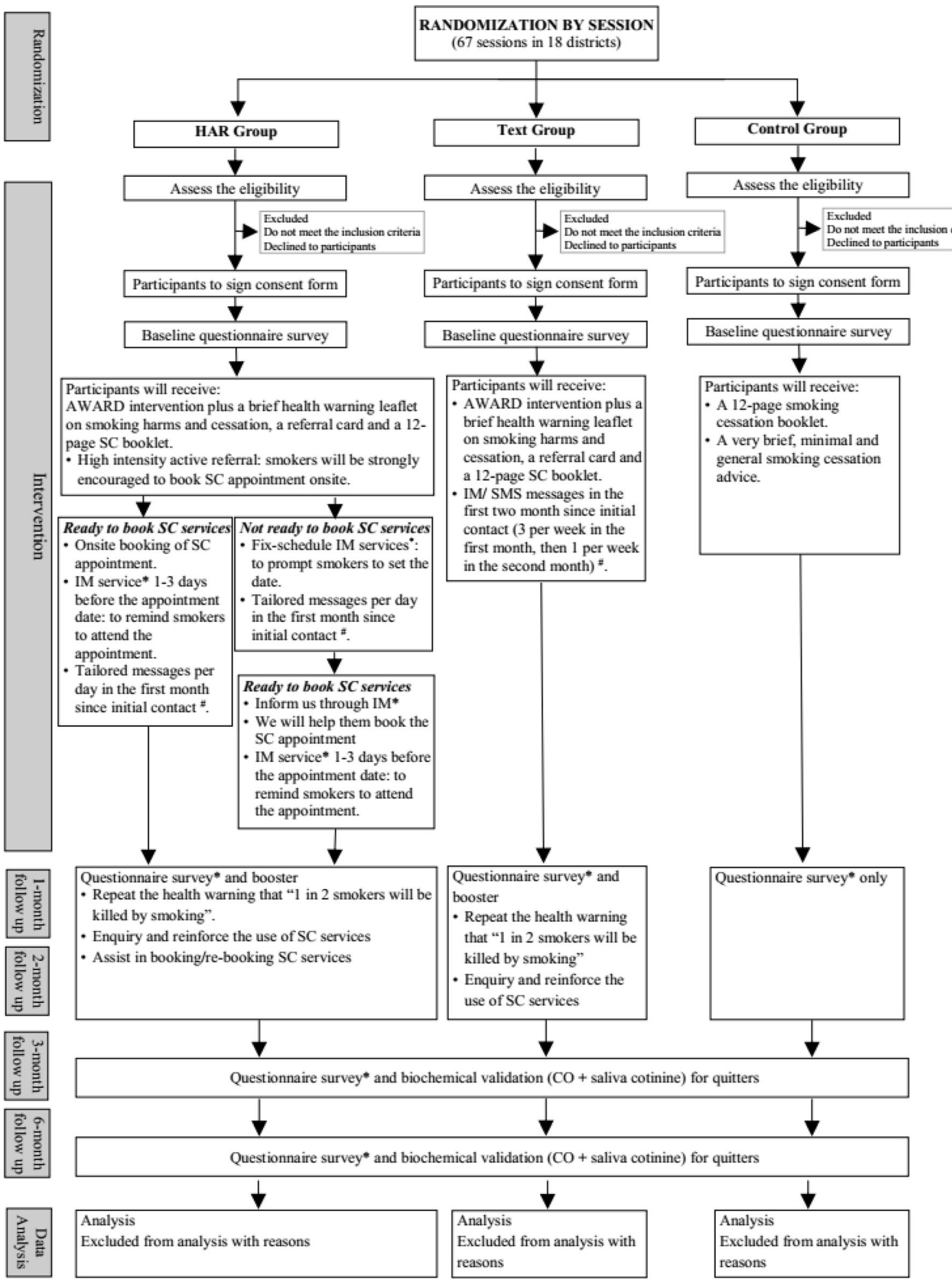

* SMS or telephone call will be used for those who do not preferring using IM.

"Smokers will be reminded, in the first message, to return us a simple message if they do not want to receive the message at any time during the study period.

Fig. 1 Study design 
containing SC and recruitment information will be set up in shopping malls and public areas. Using persuasive techniques such as the 'foot-in-the-door' method [23], SC ambassadors will ask smokers simple questions (e.g., daily cigarette consumption, history of smoking, general health status) to arouse their interest in participating in the Contest. Informed consent for voluntary participation will be obtained from the eligible participants before administering the baseline questionnaire.

\section{Randomization and blinding}

cRCT design will be used in which all participants will be randomly assigned to 1 of the 3 groups based on the recruitment session. The randomization of group assignment will be generated before recruitment. One investigator who does not participate in recruitment will randomly generate blocks, with each block size equal to 3,6 or 9, containing a random permutation of the 3 RCT groups. The numbers for the permutation in the blocks will be generated from the website http://www.random.org (a website for generating random integers), and then merge with the list of all recruitment days. As the intervention cannot be completely blinded in this study, the RCT is single-blinded that all outcome assessors and data analysts will be blinded to group allocation.

\section{Sample size and power analysis}

The computer program G*Power is used to calculate the sample size [24]. The proposed sample size is based on the primary outcome of self-reported 7-day point prevalence of abstinence (PPA) at 3 months. Based on the QTW study in 2015, the 3-month PPA for the moderate-intensity active referral intervention and the control group was 18.7 and $14 \%$, respectively [11]. Therefore, the effect size (odds ratio) for the intervention in the present study is set conservatively at 1.33. To detect a significant difference in quit rate with a power of $80 \%$ and a significance level of 5\%, 971 participants in each arm are required. Given the limited resources and recruitment period, the maximum total sample size is 1200 (400 per group). The $p$-value and the power for testing the expected effect size (1.54) will be 0.08 and $57.3 \%$.

\section{Interventions}

Each RCT group consists of one or a combination of the following components as the intervention. The detail is shown in Table 1.

\section{On-site active referral for HAR group}

Interventions in HAR group are designed to promote the use of the existing SC services to increase abstinence. Five major cessation services in Hong Kong will be involved. They had successful collaboration with the Contest in 2015, and their characteristics were reported previously $[11,25]$. Well-trained SC ambassadors will assist on-site booking for SC services based on participants' preferred services providers and available time. For participants who are not ready to seek SC services at on-site, they will be encouraged to set a date for appointment booking. SC ambassadors will follow them through the telephone at 1 week. They can also inform us through instant messages or telephone calls anytime between 1-week and 1-month. SC ambassadors will help participants book the appointment once receiving their decisions on SC services providers, preferred time and clinics.

\section{Tailored messages for HAR group}

Tailored, automatic, and fix-schedule messages will be sent once per day for the first month (or stop upon request by the smokers) via instant messaging (IM) services (e.g., WhatsApp, WeChat) since initial contact. For smokers who do not use or refuse to receive IM messages, they will be contacted via short messaging service (SMS) or telephone calls. Contents of the tailored messages will be developed through a qualitative study using openended questions in participants of QTW 2014. Tailored messages will include (1) brief health warning, (2) benefits of quitting, (3) SC services and their effectiveness (4) story about pleasant experiences and successful quitting of smokers in the past, and (5) readiness to make and be adherent to SC appointments.

Details of successfully booked SC appointment, such as SC services address, contact information, date, and appointment number will be delivered to the smokers using messages or telephone calls. All smokers will receive a reminder-to-attend message or telephone call 1-3 days before the appointment date. Research staff will monitor the use of SC services by smokers at each follow-up (1-, 2-, 3- and 6-months) and assist participants to book or re-book the appointments if necessary. We shall liaise with the existing service providers and seek their assistance in helping the smokers in a timely manner.

Table 1 Summary of intervention in 3 groups

\begin{tabular}{lll}
\hline & HAR Group & Text Group \\
\hline Onsite active referral + tailored messages & $\checkmark$ & $\checkmark$ \\
Text messaging & $\checkmark$ & $\checkmark$ \\
AWARD advice + health warning leaflet + referral card + self-help booklet & & $\checkmark$ \\
General brief advice + self-help booklet & \\
\hline
\end{tabular}




\section{Text messaging for Text group}

The text-messaging intervention aims to motivate smokers to book the SC appointments by themselves. They will be introduced (using the referral card) and motivated to use the SC services at onsite. IM/SMS messages (3 per week in the first month, then 1 per week in the second month) will be sent to encourage them to book an SC appointment since initial contact. A total of 16 messages will be sent to the smokers. The messages will be simpler and more generic than the messages in HAR group. Research staff will monitor the SC services use at each follow-up (1-, 2-, 3- and 6-months) and encourage smokers to book or re-book the appointment if necessary. This is a much cheaper and brief method than HAR group.

\section{AWARD advice for HAR and Text groups}

AWARD model-guided advice will be delivered to smokers onsite, which include (1) ask about smoking history, (2) warn the subject about the increased risk of premature death (with a brief health warning leaflet, see below for information), (3) advise the subject to quit immediately, (4) refer the subject to existing cessation services (with a referral card, see below for information), and (5) do it again if the subject fails to quit. The whole process of AWARD can be delivered within $30 \mathrm{~s}$ to $1 \mathrm{~min}$. The model has been validated in our previous trials $[11,17-20]$.

\section{Self-help materials}

Following the previous trial in 6th QTW in 2015 [25], the 2-side health warning leaflet, which systematically covers the most important messages to motivate SC, as well as the pocket size referral card will be disseminated to the smokers in the 2 intervention groups. The content of referral card includes brief information and highlights of existing SC services, contact details, available therapies, and incentive information.

All participants in 3 groups will receive a 12-page self-help booklet developed by the $\mathrm{COSH}$. The content includes information about benefits of quitting, smoking and diseases, methods to quit, how to handle withdrawal symptoms, declaration of quitting, etc.

\section{General brief advice for Control group}

Participants in the control group will receive very brief, minimal and general SC advice, such as "Please quit smoking for improving health and save money", "Please refer to the self-help booklet for the details about smoking cessation" and "Please call us if you have any enquiry".

\section{Data collection}

\section{Baseline}

The baseline questionnaire data includes four parts and will be collected by trained SC ambassadors. The first part measures participants' smoking status (e.g., average number of cigarettes smoked per day, the age of starting smoking and the usual time having the first cigarette smoked each day, attempts to quit or reduce, methods used in past quitting attempts, etc.). The second part measures participants' readiness to quit, and perceived importance, difficulties and confidence to quit smoking. The third part asks participants' knowledge about smoking (e.g., e-cigarette and risk of smoking). The final part collects sociodemographic data (e.g., sex, age, education level, number of children, occupation, marital status, annual income, etc.).

\section{Follow-up}

The follow-up surveys will be conducted by telephone at 1, 2, 3 and 6 months after the baseline. A set of questionnaire similar to the baseline questionnaire will be used to collect information on smoking behavior, quit attempts, smoking-related psychological factors and perceived social support in the quitting process, and the use of referred SC services. Participants who reported 7-day PPA at 3 and 6 months will be invited for a biochemical validation using the exhaled carbon monoxide (CO) and saliva cotinine tests.

\section{Outcome assessments}

The primary outcome is self-reported 7-day PPA at 3 and 6 months.

Secondary outcomes include:

1. SC services use: calling a hotline of the SC services, booking an appointment, SC clinic attendance, counselling session attendance, and other indicators to be further specified after liaison with the existing $\mathrm{SC}$ services (e.g. services providers' records on services utilization). The number of referrals will be calculated for the baseline and 1-, 2-, 3- and 6-month follow-ups.

2. Biochemically-verified past 7-day PPA using exhaled-air $\mathrm{CO}$ levels $<4 \mathrm{ppm}$ and saliva cotinine concentration $<10 \mathrm{ng} / \mathrm{ml}[26,27]$.

3. Smoking reduction is defined as daily cigarette consumption reduction by $>50 \%$ compared with baseline.

\section{Data analysis}

Data will be entered into SPSS for Windows (version 23). Descriptive statistics such as frequency, percentage, and mean will be used to summarise the outcomes and other variables. The main analysis will be a comparison between both intervention groups and the control group for the proportions of smoking abstinence at 3 and 6 months, using chi-square tests and odds ratios with 95\% confidence intervals. Generalized Estimating Equation 
(GEE) models will be applied to test the intervention effect, to identify the baseline predictors of successful quitting and to assess the changes in smoking-related factors over time. Intention-to-treat (ITT) analysis will be used in which participants who lose contact or drop out in the follow-ups will be treated as a failure to achieve any cessation outcome. Multiple imputations will be used to compute missing data for outcome variables.

\section{Discussion}

To the best of our knowledge, this is the first RCT conducted to evaluate whether high-intensity active referral to $\mathrm{SC}$ services is more effective than low intensity of SC referral by using text messaging in achieving abstinence among smokers in the community. Since the efficiency of active referral of SC services (moderate level of SC active referral by collecting smokers' details and send to SC providers for follow-up) has been proved in the previous trial [11], the present study explores further by comparing the efficacy of the 2 different intensities of SC active referral. We also expect that active referral with high intensity will achieve high rates on smoking abstinence and smoking reduction by comparing the effectiveness of HAR, moderate level SC active referral and text-messaging referral in a 2-year combined model.

This study has several significant strengths. Firstly, most SC service referral studies were conducted in the health care settings $[10,28-30]$; research conducted in the community settings is scarce [11]. The study fills this gap by providing an active referral intervention for community smokers who are not usually self-initiated to seek SC assistance. Secondly, follow-up assessments will be carried out at 1, 2, 3 and 6 months which allows us to keep longitudinal tracking on the effects of the active referral interventions on abstinence and changes in smoking-related psychosocial factors. Thirdly, the intervention approaches in this study (e.g., on-site active referral, text messaging, AWARD advice, referral card, self-help booklet) are brief and flexible. They can reach large numbers of community smokers at relatively low cost [11]. Therefore, the findings obtained will have significant implications for SC practice. Finally, the study will also have important implications for current SC policy, given the low utilization of SC services and a large number of cigarette smokers. If the intervention is effective in helping smokers to quit, our findings will address the active role of community health workers and SC service providers in promoting $\mathrm{SC}$ in the community.

\section{Abbreviations}

AWARD: Ask, Warn, Advice, Refer and Do-it-again; CO: Carbon monoxide; CONSORT: Consolidated Standards of Reporting Trials; COSH: Hong Kong Council on Smoking and Health; GEE: Generalized Estimating Equation; HAR: High-intensity active referral; IM: Instant messaging; ITT: Intention-to-treat; NGOs: Non-governmental organizations; PPA: Point prevalence abstinence;
QTW: Quit to Win; RCT: Randomized controlled trial; SC: Smoking cessation; SMS: Short messaging service

\section{Acknowledgements}

The authors would like to thank the participants, helpers from the universities and non-governmental organizations and research assistants who involved in this study.

\section{Funding}

This study is funded by the Hong Kong Council on Smoking and Health.

\section{Availability of data and materials}

The datasets generated and/or analysed during the current study are available from the corresponding author on reasonable request.

\section{Authors' contributions}

MPW, YNS, THL participated in study concept and design. MPW and YNS participated in conducting the study. XW and MPW drafted the manuscript. HCL, YW, YTC, CSK, WYL and SCC provided critical comments. All authors have read and approved the final manuscript.

\section{Ethics approval and consent to participate}

The study has been approved by the research ethics committee of the University of Hong Kong and the Hong Kong West Cluster of the Hospital Authority (IRB reference no.: UW16-320). The trial was registered at Clinicalstrials.gov as NCT02804880. The study poses a minimal additional risk to study participants. Written consent will be obtained from the eligible participants for their voluntary participation in the study and agreement to allow us to transfer their contact information to their chosen SC service providers.

\section{Consent for publication}

Not applicable.

\section{Competing interests}

Dr. Man Ping Wang is an Associate Editor for BMC Public Health. The other authors declare that they have no competing interests.

\section{Publisher's Note}

Springer Nature remains neutral with regard to jurisdictional claims in published maps and institutional affiliations.

\section{Author details}

${ }^{1}$ School of Nursing, University of Hong Kong, 4/F, William MW Block, 21 Sassoon Road, Pokfulam, Hong Kong SAR. ²Department of Psychiatry, University of Hong Kong, 2/F, New Clinical Building, Queen Mary Hospital, 102 Pokfulam Road, Pokfulam, Hong Kong SAR. ${ }^{3}$ Hong Kong Council on Smoking and Health, Unit 44-2-03, 44/F, Hopewell Centre, 183 Queen's Road East, Wanchai, Hong Kong SAR. ${ }^{4}$ School of Public Health, University of Hong Kong, G/F, Patrick Manson Building (North Wing), 7 Sassoon Road, Pokfulam, Hong Kong SAR

Received: 19 April 2018 Accepted: 29 June 2018

Published online: 04 July 2018

\section{References}

1. WHO report on the global tobacco epidemic 2017: Monitoring tobacco use and prevention policies. 2017. https://escholarship.org/uc/item/8nw5p0zt. Accessed 30 Mar 2018.

2. Census and Statistics Department. Thematic Household Survey, Report no. 64: pattern of smoking. Hong Kong: Hong Kong SAR Government; 2018.

3. Borland R, Borland R, Segan CJ, Borland R, Segan CJ. The potential of quitlines to increase smoking cessation. Drug Alcohol Rev. 2006;25(1):73-8. https://doi.org/10.1080/09595230500459537.

4. Fiore MC, Jaen CR, Baker T, Bailey W, Benowitz N, Curry S, Dorfman S, Froelicher E, Goldstein M, Healton C, et al. Treating tobacco use and dependence: 2008 Update, Clinical practice guideline. Rockville: US Department of Health and Human Services, Public Health Service; 2008.

5. Stead LF, Buitrago D, Preciado N, Sanchez G, Hartmann-Boyce J, Lancaster T. Physician advice for smoking cessation. Cochrane Database Syst Rev. 2013(5) https://doi.org/10.1002/14651858.CD000165.pub4. 
6. Thomsen T, Villebro N, Møller AM. Interventions for preoperative smoking cessation. Cochrane Database Syst Rev. 2014(3) https://doi.org/10.1002/ 14651858.CD002294.pub4.

7. Policy recommendations for smoking cessation and treatment of tobacco dependence. 2015. http://www.who.int/tobacco/publications/smoking_ cessation/recommendations/en/. Accessed 30 Mar 2018.

8. McDonald PW. Population-based recruitment for quit-smoking programs: an analytic review of communication variables. Prev Med. 1999;28(6):545-57. https://doi.org/10.1006/pmed.1998.0479.

9. Guy MC, Seltzer RGN, Cameron M, Pugmire J, Michael S, Leischow SJ. Relationship between smokers' modes of entry into Quitlines and treatment outcomes. Am J Health Behav. 2012;36(1):3-11.

10. Borland R, Balmford J, Bishop N, Segan C, Piterman L, McKay-Brown L, Kirby C, Tasker C. In-practice management versus quitline referral for enhancing smoking cessation in general practice: a cluster randomized trial. Fam Pract. 2008;25(5):382-9. https://doi.org/10.1093/fampra/cmn046.

11. Wang $M$, Suen $Y$, Li W, et al. Intervention with brief cessation advice plus active referral for proactively recruited community smokers: a pragmatic cluster randomized clinical trial. JAMA Intern Med. 2017. https://doi.org/10. 1001/jamainternmed.2017.5793.

12. Cheung YTD, Wang MP, Li HCW, Kwong A, Lai V, Chan SSC, Lam T-h. Effectiveness of a small cash incentive on abstinence and use of cessation aids for adult smokers: a randomized controlled trial. Addict Behav. 2017;66:17-25.

13. Abroms LC, Boal AL, Simmens SJ, Mendel JA, Windsor RA. A randomized trial of Text2Quit: a text messaging program for smoking cessation. Am J Prev Med. 2014;47(3):242-50.

14. Free C, Knight R, Robertson S, Whittaker R, Edwards P, Zhou W, Rodgers A, Cairns J, Kenward MG, Roberts I. Smoking cessation support delivered via mobile phone text messaging (txt2stop): a single-blind, randomised trial. Lancet. 2011;378(9785):49-55. https://doi.org/10.1016/S0140-6736(11)60701-0.

15. Borland R, Balmford J, Benda P. Population-level effects of automated smoking cessation help programs: a randomized controlled trial. Addiction. 2013;108(3):618-28. https://doi.org/10.1111/j.1360-0443.2012.04091.x.

16. Scott-Sheldon LA, Lantini R, Jennings EG, Thind H, Rosen RK, SalmoiragoBlotcher E, Bock BC. Text messaging-based interventions for smoking cessation: a systematic review and meta-analysis. JMIR Mhealth Uhealth. 2016;4(2) https://doi.org/10.2196/mhealth.5436.

17. Chan SS, Wong DC, Cheung YT, Leung DY, Lau L, Lai V, Lam TH. A block randomized controlled trial of a brief smoking cessation counselling and advice through short message service on participants who joined the quit to win contest in Hong Kong. Health Educ Res. 2015;30(4):609-21. https:// doi.org/10.1093/her/cyv023.

18. Chan SCC, Wong DCN, Cheung DYT, Lam COB, Lau LMM, Lai WWY, Lam TH. "Quit to win 2012" and smoking cessation. Hong Kong: Hong Kong Council on Smoking and Health; 2014.

19. Chan SSC, Wong DCN, Lau LMM, Lai WWY, Lam COB, Lam TH. "Quit to win 2010" and smoking cessation. Hong Kong: Hong Kong Council on Smoking and Health; 2013.

20. Wang MP, Li WH, Cheung YT, Lam OB, Wu Y, Kwong AC, Lai WW, Chan SS, Lam TH. Brief advice on smoking reduction versus abrupt quitting for smoking cessation in Chinese smokers: a cluster randomized controlled trial. Nicotine Tob Res. 2017; https://doi.org/10.1093/ntr/ntx026.

21. Schulz KF, Altman DG, Moher D. CONSORT 2010 statement: updated guidelines for reporting parallel group randomised trials. Int I Surg. 2011; 9(8):672-7. https://doi.org/10.1136/bmj.c332.

22. Hyland A, Borland R, Li Q, Yong HH, McNeill A, Fong GT, O'Connor RJ, Cummings KM. Individual-level predictors of cessation behaviours among participants in the international tobacco control (ITC) four country survey. Tob Control. 2006;15 Suppl 3:iii83-94. https://doi.org/10.1136/tc.2005.013516.

23. Freedman JL, Fraser SC. Compliance without pressure: the foot-in-the-door technique. J Pers Soc Psychol. 1966;4(2):195.

24. Faul F, Erdfelder E, Lang A-G, Buchner A. G* power 3: a flexible statistical power analysis program for the social, behavioral, and biomedical sciences. Behav Res Methods. 2007;39(2):175-91.

25. Suen YN, Wang MP, Li WH, Kwong ACS, Lai WW, Chan SSC, Lam TH. Brief advice and active referral for smoking cessation services among community smokers: a study protocol for randomized controlled trial. BMC Public Health. 2016;16(1):387. https://doi.org/10.1186/s12889-016-3084-z.

26. Javors MA, Hatch JP, Lamb RJ. Cut-off levels for breath carbon monoxide as a marker for cigarette smoking. Addiction. 2005;100(2):159-67. https://doi. org/10.1111/j.1360-0443.2004.00957.x.
27. Cooke F, Bullen C, Whittaker R, McRobbie H, Chen M-H, Walker N. Diagnostic accuracy of NicAlert cotinine test strips in saliva for verifying smoking status. Nicotine Tob Res. 2008;10(4):607-12. https://doi.org/10. 1080/14622200801978680

28. Tindle HA, Daigh R, Reddy VK, Bailey LA, Ochs JA, Maness MH, Davis EM, Schulze AE, Powers KM, Ylioja TE, et al. eReferral between hospitals and quitlines: an emerging tobacco control strategy. Am J Prev Med. 2016;51(4): 522-6. https://doi.org/10.1016/j.amepre.2016.05.024.

29. Vidrine II, Shete S, Cao Y, Greisinger A, Harmonson P, Sharp B, Miles L, Zbikowski SM, Wetter DW. Ask-advise-connect: a new approach to smoking treatment delivery in health care settings. JAMA Intern Med. 2013;173(6): 458-64. https://doi.org/10.1001/jamainternmed.2013.3751.

30. Sheffer MA, Baker TB, Fraser DL, Adsit RT, McAfee TA, Fiore MC. Fax referrals, academic detailing, and tobacco quitline use: a randomized trial. Am J Prev Med. 2012:42(1):21-8. https://doi.org/10.1016/j.amepre.2011.08.028.

\section{Ready to submit your research? Choose BMC and benefit from:}

- fast, convenient online submission

- thorough peer review by experienced researchers in your field

- rapid publication on acceptance

- support for research data, including large and complex data types

- gold Open Access which fosters wider collaboration and increased citations

- maximum visibility for your research: over $100 \mathrm{M}$ website views per year

At BMC, research is always in progress.

Learn more biomedcentral.com/submissions 